\title{
FENOMENOLOGIA E TEORIA DO CONHECIMENTO EM HUSSERL
}

\author{
Phenomenology and Theory of Knowledge in Husserl
}

Fenomenología y Teoría del Conocimiento en Husserl

URBANO ZILLES

\begin{abstract}
Resumo: O texto apresenta a construção da fenomenologia em torno de uma teoria do conhecimento. Principia pelo contexto filosófico do surgimento da fenomenologia, apontando as relações entre a perspectiva de Husserl e a Teoria do Conhecimento de Hermann Cohen. Faz um relato das principais obras de Husserl, destacando sua progressão, de uma crítica ao psicologismo à estruturação de uma fenomenologia transcendental, até alcançar temas como o corpo e o mundo-da-vida. O texto apresenta os principais conceitos da fenomenologia, situando-a como uma filosofia rigorosa.
\end{abstract}

Palavras-chave: Fenomenologia; Teoria do Conhecimento; Husserl.

\begin{abstract}
This paper presents the construction of phenomenology around a theory of knowledge. It begins by the philosophical context of appearance of phenomenology, pointing the relations between Husserl's perspective and the Theory of Knowledge of Hermann Cohen. After that, it relates the main works of Husserl, to make salient his progression, since the critique of psychologism to the development of transcendental phenomenology, to subjects like the body and life-world. The paper presents the main concepts of phenomenology, putting is place like a rigorous philosophy.
\end{abstract}

Keywords: Phenomenology; Theory of Knowledge; Husserl.

Resumen: El texto exhibe la construcción de la fenomenología en torno de una teoría del conocimiento. Comienza por el contexto filosófico del surgimiento de la fenomenología, señalando las relaciones entre la perspectiva de Husserl y la Teoría del Conocimiento de Hermann Cohen. Hace un relato de las principales obras de Husserl, resaltando su progresión, desde una crítica al psicologismo hasta la estructuración de una fenomenología trascendental, alcanzando temas como el cuerpo y el mundo de la vida. El texto presenta los principales conceptos de la fenomenología, localizándola como una filosofía estricta.

Palabras-claves: Fenomenología; Teoría del Conocimiento; Husserl.

A influência da Fenomenologia de Edmund Husserl (1859-1938) foi tamanha que hoje se tornou difícil avaliá-la em toda a sua extensão e profundidade. A recepção de sua obra começou pouco antes da Primeira Guerra Mundial e teve certo apogeu na década de 1920. Nessa época surgiram Escolas que desenvolveram alguns aspectos de sua concepção, como é o caso da ontologia existencial de Martin Heidegger e a ética dos valores de Max Scheler.

\section{Contexto Filosófico}

No final do século XIX, a psicologia não só gozava de grande prestígio, mas para muitos parecia a chave de explicação da teoria do conhecimento e da lógica. Para rejeitar essa tese, Edmund Husserl elaborou seu método fenomenológico, produzindo uma obra gigantesca em extensão e profundidade que desafia seus intérpretes até hoje.

Na primeira década do século XX, poucos historiadores consideravam a obra de Husserl. Suas Investigações Lógicas (1900/1901), em vista das numerosas pesquisas neokantianas no campo da epistemologia, chamavam pouca atenção. Na verdade, pareciam muito próximas da tese de Hermann Cohen de que a lógica deve ser fundamento de um sistema filosófico. Da mesma forma, o ideal da pureza e o postulado da fundamentação da filosofia, sobretudo da teoria do conhecimento, da matemática ou das ciências naturais também podia encontrar-se em Cohen.

Hermann Cohen (1842-1918) buscava um último axioma no qual todo o ser identificado com o pensamento pudesse ser derivado e explicado. Via tal princípio no vir-aser. A pesquisa sobre o fundamento, que o pensamento matemático deve seguir, em Cohen exerce um papel central. Chama atenção seu esforço para restaurar a filosofia com o status de uma teoria universal da ciência.

A teoria do conhecimento de Cohen tem caráter duplo: por um lado, busca um a priori irredutível, separando conhecimento de experiência, situando-o no puro pensamento; por outro, tenta conciliar o mundo das idéias da lógica pura com o pensamento de Heráclito sobre o devir. Entende a pureza, não como isolamento, mas sob o aspecto de sua aplicação. Propõe que a filosofia, analogamente ao processo da análise infinitesimal, se adapte ao processo. Cohen procura mostrar que as sensações e a ciência experimental a elas relacionada são perfeitamente reconstruíveis pelo pensamento, sem que algo fique de fora. 
Enquanto Cohen atribuíra ao pensamento a dimensão de fim em si mesmo, Husserl tentou superar a aporia do neokantismo, que diluíra o ser racionalmente no puro pensamento, fundando o ideal de uma lógica pura na empiria. Vindo de Franz Brentano (1838-1917), com o qual estudara em Viena, primeiro Husserl via conceitos fundamentais da matemática ou aritmética numa psicologia descritiva. Isso está evidenciado em sua obra Sobre o Conceito de Número, publicada em 1887.

Desde o começo Husserl tem o objetivo de superar a oposição entre objetivismo e subjetivismo. No final do século XIX, ainda reinava um fascínio pelo ideal do conhecimento das ciências da natureza. Husserl quer satisfazer à objetividade do conhecimento, seja ele ideal ou real, e à subjetividade do cognoscente. No seu ensaio de Filosofia da Aritmética (1891) manifesta seu objetivo, mas sucumbe ao psicologismo.

O psicologismo defendia a tese de que a lógica compreende as normas que valem para todo o pensamento certo da mesma maneira como a engenharia apresenta as regras para construir bem. Por isso, como a engenharia se fundamenta na física, a lógica se fundamentaria na psicologia.

Rejeitando o psicologismo, Husserl afirma que as proposições lógicas contêm verdades necessárias, puramente ideais; as proposições da psicologia generalizam interpretações da experiência. A psicologia pressupõe a existência de seus objetos e a lógica não. Pela crítica ao psicologismo Husserl pensa a propriedade dos atos de pensar, perceber etc., a partir do seu conteúdo de sentido, ou seja, do pensado e percebido.

No decurso da elaboração da fenomenologia, Husserl concentra seu interesse sempre mais nos seguintes problemas: a) Como o mundo real em sua temporalidade, em sua consistência intersubjetiva, em sua objetividade se constitui em nossa consciência? b) Como passar da atitude natural para a atitude filosófica?

No primeiro volume das Investigações Lógicas (1900), cujo subtítulo é Prolegomena para uma lógica pura, tenta mostrar que a lógica é a priori para uma teoria da ciência. Husserl rejeita a idéia de que os fundamentos de uma lógica normativa e de uma teoria do conhecimento se encontram na psicologia. Da mesma maneira não aceita a conseqüência empírica do psicologismo, no sentido de que as leis do pensamento também sejam as leis da natureza, que produziria o pensar racional. Critica, sobretudo, as concepções de Stuart Mill (1806-1873) e Herbert Spencer (1820-1903) que tentaram fundamentar a lógica antropologicamente. Husserl critica, outrossim, o psicologismo na lógica, que é comum a essas posições, por conduzir a um relativismo cético. Diante isso, Husserl persegue as condições que possibilitam ciência ou teoria em geral. Distingue dois campos da lógica pura: de um lado, a lógica das categorias de significação (como conceito, proposição, conclusão, etc.) e, de outro, a lógica das categorias objetivas (como objeto, conteúdo, unidade, pluralidade, relação, etc.). Dentro dessa esfera de essências ideais, distingue, mais uma vez, entre um sistema de categorias semióticas e outro sistema objetivo para o qual o primeiro indica. Entre ambos existe uma correlação. Mais tarde, designou esses dois sistemas com os termos de lógica apofântica e lógica formal ou ontologia formal e teoria formal dos objetos.

No segundo volume das Investigações lógicas, com o subtítulo Investigações sobre fenomenologia e teoria do conhecimento, desenvolve, programaticamente, pela primeira vez, o método fenomenológico. Elabora esse tema, de maneira mais clara, na obra publicada em 1913, Idéias para uma fenomenologia pura e uma filosofia fenomenológica. Nas Investigações Lógicas aparece indicado, de modo ainda impreciso, o aspecto do noemático. Por noema Husserl entende o conteúdo temático do conhecimento em oposição à noese como o próprio ato da vivência, que tem o noema como objeto.

\section{Fundamentação da Fenomenologia}

Husserl nega que as leis lógicas, sustentáculos da unidade de toda ciência, possam ser fundamentadas na psicologia, ciência empírica. Com isso o psicologismo não consegue resolver o problema fundamental da teoria do conhecimento, ou seja, o problema de como é possível alcançar objetividade. Coloca a questão nos seguintes termos: como é possível que o sujeito cognoscente alcance, com certeza e evidência, uma realidade que lhe é exterior? A noese são os atos pelos quais a consciência visa um certo objeto de uma certa maneira, e o conteúdo ou significado desses objetos visados é o noema. No nível transcendental, as noeses são os atos do sujeito constituinte que criam os noemas enquanto puras idealidades ou significações. As noeses empíricas são passivas, porque visam uma significação preexistente; a noese transcendental é ativa, porque constitui as próprias significações ideais.

Para Husserl, a fenomenologia é o acabamento da tentativa de Descartes de fundamentar todo o conhecimento na certeza reflexiva do ego cogito e de suas cogitationes. A reflexão fenomenológica parte da correlação de cada cogito com seu cogitatum, que nunca é um objeto isolado, mas desde logo deve ser concebido como objeto em seu mundo. Nas Conferências de Paris, Husserl afirma que tudo que é mundano, tudo que é espácio-temporal é para mim, na medida em que o vivencio, percebo, lembro, penso, julgo, valorizo, desejo, etc.

Tudo isso Descartes designa com o cogito. O mundo não é outra coisa para mim que o consciente em tais $\mathrm{CO}$ gitationes (Husserl, 1992). O "eu penso" cartesiano apresenta aquele caráter a priori necessário e absoluto, sem o qual a filosofia é impossível, porque ver-se-ia lançada na contingência das coisas empíricas e jamais poderia pen- 
sá-las como apodíticas. O cogito permanece idêntico sob a multiplicidade das vivências.

Husserl afirma que a atitude natural, não-fenomenológica, faz o homem olhar o mundo de maneira ingênua como mundo dos objetos. A fenomenologia, ao contrário, busca uma fundamentação totalmente nova, não só da filosofia, mas também das ciências singulares. Enquanto as ciências positivas consideram os objetos como independentes do observador, a fenomenologia tematiza o sujeito, o eu transcendental, que "coloca" os objetos.

O primeiro passo do método fenomenológico consiste em abster-se da atitude natural, colocando o mundo entre parênteses (epoqué). Isso não significa negar sua existência, mas metodicamente renunciar ao seu uso. Ao analisar, após essa redução fenomenológica, a corrente de vivências puras que permanecem, constata que a consciência é consciência de algo. Esse algo chama de fenômeno.

Husserl usou o termo fenomenologia, pela primeira vez, nas Investigações Lógicas (1901), em lugar da expressão "Psicologia Descritiva”, que usara até então. A consciência funda sentido como compreensão de algo que é (sentido do ser), através da intencionalidade, ou seja, através de sua orientação intencional para encher o vazio. O conceito de intencionalidade da consciência, por isso, é fundamental e constitutivo na fenomenologia de Husserl. Nela constituem-se os cogitata do cogito, os "objetos” da consciência. A intencionalidade constitui síntese ou unidade, uma constituição ativa e passiva. Esse conceito de síntese distingue-se do tradicional, pois não se limita à síntese no juízo.

Para Husserl, a fenomenologia é uma descrição da estrutura específica do fenômeno (fluxo imanente de vivências que constitui a consciência) e, como estrutura da consciência enquanto consciência, ou seja, como condição de possibilidade do conhecimento, o é na medida em que ela, enquanto consciência transcendental, constitui as significações e na medida em que conhecer é pura e simplesmente apreender (no plano empírico) ou constituir (no plano transcendental) os significados naturais e espirituais.

Para entender essas funções até sua dimensão de profundidade em sua abrangência, necessita-se do método da redução fenomenológica. A redução fenomenológica, conceito fundamental na fenomenologia de Husserl, tem o sentido de tematizar a consciência pura. Começa com a colocação entre parênteses do mundo. Prossegue na redução eidética, termo usado para o procedimento metódico que leva à visão da essência. A meta da redução eidética é a compreensão do a priori como eidos (essência). O pressuposto é que a já existente oposição entre sujeito e objeto é superada para voltar-se à análise dos dados constituintes na consciência que é "consciência de...", pondo-se o mundo com seus objetos ao eu (consciência). A consciência é intencionalidade significa: dirige-se para, visa alguma coisa. Toda consciência é consciência de.

\section{Filosofia Radical}

Para entender a fenomenologia de Husserl, é preciso compreender como ele apresenta a estrutura da consciência como intencionalidade. Se todo o sentido e valor a dar ao Ser se baseiam em funções intencionais, com essa redução, o eu se manifesta como condição de possibilidade de ter em vista o mundo (fenômeno). Sob esse aspecto, a redução conduz ao eu como subjetividade. Assim, pela redução fenomenológica, chega-se, de maneira reflexiva, ao conhecimento do eu como fonte original de toda a certeza e de todo o saber e ter do mundo. Nesse sentido, todo o conhecimento filosófico fundamenta-se como "conhecimento universal de si mesmo". Toda a filosofia husserliana resume-se, em grandes linhas, como filosofia transcendental enquanto análise da constituição da subjetividade transcendental. Seu princípio metodológico é a tentativa de descrever a vida da consciência como se apresenta à reflexão. Pretende purificar a filosofia transcendental iniciada por Kant, distinguindo seu trabalho através da elaboração do método e construção sistemática.

$\mathrm{Na}$ abordagem desses problemas, percebe-se como o foco de interesse de Husserl, na pesquisa, muda e evolui. Primeiro queria elaborar apenas uma teoria da lógica pura, delimitando o psicologismo. Aos poucos, moveuse sempre mais para o terreno da análise da consciência. Específico do método fenomenológico é servir-se, no procedimento, de conceitos psicológicos (vivência, percepções, etc.), prescindindo de seus componentes empíricos, para chegar a uma ideação independente da experiência. Husserl funda sua pesquisa na introspecção, construindo um mundo de objetos ideais.

Nesse processo ocupa lugar central o princípio da intencionalidade, um conceito que Husserl herdou da psicologia descritiva de Brentano. A intencionalidade, segundo Brentano, constitui uma característica do psíquico, a relação com um objeto. Tal relacionar-se ou orientar-se pertence ao sentido do psíquico: eu vejo, eu amo, valorizo algo. Isso não decorre do simples encontro de um corpo com outro, pois os atos psíquicos permanecem eles mesmos quando o objeto visado é irreal ou ideal / engano da percepção ou ocupação com “coisas” abstratas.

Quando se indaga das razões fundamentais do empenho de Husserl na busca das leis essenciais últimas, certamente o motivo é a justificação da filosofia como saber rigoroso e científico. Em 1911, no artigo A filosofia como ciência de rigor, afirma na conclusão:

A filosofia, porém, é por essência uma ciência dos inícios verdadeiros, das origens, dos rizómata pánton. A ciência do radical tem que proceder também radicalmente, e sob todos os respeitos. Sobretudo ela não deve descansar antes de ter chegado aos seus inícios, isto é, aos seus problemas absolutamente claros, aos métodos delineados no próprio sentido desses problemas, e ao campo ínfimo da elaboração das coisas de apresentação absolutamente clara (Husserl, 1965, p. 72). 


\section{Desafio para a Fenomenologia}

Depois de 1900, a filosofia foi desafiada pelas ciências empíricas nos meios acadêmicos. Os docentes de filosofia, nas Faculdades, tentavam recuperar seu papel de liderança no mundo do saber. Nesse contexto, Husserl quer consolidar a filosofia no status de ciência fundamental. Esse fundamento, ao contrário do que acontece nas ciências empíricas, não deveria situar-se na empiria como a priori último, mas na consciência transcendental. Por isso a filosofia fenomenológica é, em todos os sentidos, a única ciência absolutamente rigorosa, pois fornece a si própria os seus fundamentos e os de todas as outras ciências.

Husserl chegou a falar de uma situação precária da filosofia acadêmica de sua época. Na revista Lógos (I, 1911) desenvolveu seu programa no citado artigo A Filosofia como ciência de rigor. Como a fenomenologia não se baseia em dados da experiência ou vivência de realidades, sua tarefa é a pesquisa das possibilidades ideais da vivência. O meio para chegar a ela é a intuição. Afirma:

Mas é precisamente próprio da filosofia, desde que remonte às suas origens extremas, o seu trabalho científico situar-se em esferas de intuição direta, e constitui o maior passo a dar pela nossa época, reconhecer-se que a intuição filosófica no sentido autêntico, a percepção fenomenológica do Ser, abre um campo imenso de trabalho e leva a uma ciência que, sem todos os métodos indiretamente simbolizantes e matematizantes, sem o aparelho das conclusões e provas, não deixa de chegar a amplas intelecções das mais rigorosas e decisivas para toda a filosofia ulterior (Husserl, 1965, p. 73).

É surpreendente que Husserl, querendo estabelecer uma ciência de rigor, escolha uma instância cognitiva que representa um órgão do conhecimento mais indeterminado e difuso. Nisso converge com concepções da filosofia da vida, como as encontramos no intuicionismo de Henri Bergson, o qual, de resto, rejeitou como filosofia da mundividência. Assim a intuição não podia constituir um fundamento estável para o processo do conhecimento. Para isso Husserl recorreu ao argumento do cogito cartesiano. Como excluíra tudo que é empírico, através da epoqué ou colocação entre parênteses, na sua construção mental se fixava nos noemata, que são determinação formal. Dessa maneira não existe transição da abstração para as ciências. Husserl afirma, de maneira apodítica, que esses noemata são os últimos momentos transcendentais. Com isso não se evidencia grande vantagem da fenomenologia para uma teoria fundamental e uma metodologia das ciências.

Husserl percebera a dificuldade oriunda da estratégia de não partir do empírico, melhor, de colocar todo fato empírico entre parênteses. Desde o começo, tinha como meta buscar um fundamento último para toda a argumentação filosófica na consciência do eu pensado transcendentalmente. Por isso essa redução ou epoqué, colocando o empírico entre parênteses, tinha que conduzir forçosamente à suspensão do eu empírico. Entretanto, como outros pensadores contemporâneos, queria salvar esse eu. A reflexão solipsista do eu da apercepção transcendental tinha a função de conservar a individualidade, mas de uma individualidade no sentido espiritual e não de uma individualidade natural.

$\mathrm{O}$ acesso metodológico à subjetividade transcendental Husserl designa redução transcendental. Nesta, põese fundamentalmente entre parênteses a crença na existência das coisas e na existência do mundo natural e de todos os domínios que lhe estão ligados, para alcançar o terreno firme da consciência pura em que o seu correlato, que é o mundo, se transforma em mero objeto intencional. É a redução ou operação pela qual a existência efetiva do mundo exterior é "colocada entre parênteses", para que a investigação se ocupe apenas com as operações realizadas pela consciência, sem perguntar se as coisas visadas por ela existem realmente ou não.

Considerando ser da essência da reflexão que somente é possível como reflexão do eu sobre si mesmo, sobre sua própria consciência, a análise constitutiva da fenomenologia primeiro deve realizar-se como egologia. Isso, todavia, não equivale a solipsismo, pois a fenomenologia husserliana parte da certeza do Ser dos outros com os quais o eu sempre já se sabe em existência comum no mundo. Nessa certeza do ser do mundo, no qual já sempre vivemos, antes mesmo da reflexão fenomenológica, está implícita a existência do outro.

Husserl não tinha como reconhecer maior importância aos fatores empíricos. Isso já se evidencia em sua fenomenologia, fundada, inicialmente, na consciência teórica e, depois, passa à somatologia e estesiologia, de um lado, e a uma teoria da intersubjetividade, de outro. No primeiro caso, o corpo é reconhecido como fundamento último de todos os processos de vivência e, no segundo, cada indivíduo só se pode constituir na base da compreensão do outro, através do sentimento de outros indivíduos pela leitura semiótica das expressões corporais. De acordo com a concepção idealista de Husserl, o corpo (Leib) é considerado menos como substrato material que corpo (Körper) carregado de sentido.

O universo das percepções, das impressões sensíveis, de cada eu, segundo Husserl, adquire uma relação com o corpo (Leib) e seus membros como órgãos sensíveis, tornando-se ele mesmo algo "corpóreo", mas não material. Todas as ampliações, que a experiência possível pode fazer, estão vinculadas ao sentido pré-dado pela apercepção do corpo, e este sentido é determinado pela corporeidade percebida com localização também percebida. O que é localizável não é tudo. Husserl define o corpo (Leib) pela consciência da identidade: como o corpo (Körper) pode mudar constantemente, o que significa que pode perder ou ganhar algo, também podem alterar-se os campos de percepção, isso só pode ser concebido como órgão da vontade. No campo da vontade surgem movimentos livres e mudanças que são únicas. 
A reflexão fenomenológica de Husserl mostra o outro como outro, ou seja, como um eu-sujeito consciente não pode estar presente na minha consciência da mesma maneira como outros entes do mundo. Somente é dado como “apresentado" em seu corpo, numa apresentação que nunca encontra sua plenitude numa apresentação.

Por isso, o outro é o estranho do eu. Nesse caminho, a reflexão conduz para além da egologia à intersujetividade transcendental. Pode discutir-se se Husserl, através da análise constitutiva do outro, conseguiu atingir aquela dimensão na qual a transcendência do outro se manifesta na própria consciência.

\section{Teoria da Intersubjetividade e Mundo da Vida}

A teoria da intersubjetividade de Husserl, que modifica sua egologia radical até certo ponto, apóia-se, em grande parte, na psicologia do sentimento, recorrendo a elementos semióticos do pragmatismo de Charles Peirce (1830-1914). Essa influência manifesta-se, sobretudo, na exploração de conceitos como signo, expressão e sentido.

Com a idéia da semiótica abstrativa do corpo, de uma hermenêutica cotidiana prática, Husserl busca uma compreensão intersubjetiva de sentido. Não olha o mundo que o cerca de fora, de maneira objetiva, mas quer compreendê-lo exclusivamente na perspectiva do sujeito. Considera a contemplação objetiva como um obstáculo, porque, em última análise, conduziria ao positivismo, como expôs em sua obra $A$ crise da ciência européia e a fenomenologia transcendental. O mundo da vida (Lebenswelt) é dado ao sujeito como horizonte de experiência, centrada no seu eu. Está fundado fisicamente, constituindo-se em camadas desde o animal até o cultural, podendo desenvolverse ontologias regionais das diferentes camadas. Assim, em última análise, Husserl entende por mundo da vida algo espiritual. Como o conceito mais amplo de mundo, também o conceito de "mundo da vida" é, para ele, um fenômeno dado na consciência. É dado ao sujeito: "Consciência do mundo é consciência no modo da certeza da fé" (Experiência e juízo).

Com sua teoria do mundo da vida, Husserl procura um chão no qual todos os juízos predicativos, com os quais operam as ciências especializadas, possam encontrar uma referência antepredicativa. $\mathrm{O}$ recurso ao mundo da experiência é recurso ao mundo da vida, ou seja, ao mundo no qual sempre já vivemos e que fornece o ponto de partida para todas as conquistas do conhecimento e para toda a determinação científica.

Segundo Husserl, primeiro se deve perder o mundo, através da epoqué, para recuperá-lo mediante a reflexão universal sobre si mesmo. Essa é a meta e a intenção da reflexão radical. Com o conceito de "subjetividade transcendental" ou intersubjetividade, na sua obra tardia, indica o aspecto teleológico. Usa-o para esclarecer a reivindi- cação de que a fenomenologia conduz o ponto de partida de Descartes ao acabamento.

Até certo ponto, a fenomenologia pode ser compreendida como explicação do que está implícito, desde o início, no conceito de intencionalidade da consciência. Essa orienta-se para a subjetividade absoluta que se constitui de maneira transcendental, que Husserl também designa como intersubjetividade transcendental ou vida transcendental. Todo o empenho intencional realiza-se na relação entre intenção vazia e plena. Assim o próprio conceito de intencionalidade é, em sua raiz, teleológico. E a teleologia da intencionalidade é uma teleologia da razão, ou seja, transforma a razão latente em razão patente.

Já no início de $A$ crise da humanidade européia e a filosofia, Husserl afirma: "Nesta conferência quero ousar a tentativa de suscitar um novo interesse para o tão freqüentemente tratado tema da crise européia, desenvolvendo a idéia histórico-filosófica (ou o sentido teleológico) da humanidade européia" (Husserl, 2002, p. 65).

Diz:

Creio que nós sentimos (e, apesar de toda obscuridade, este sentimento provavelmente tem sua razão) que à nossa humanidade européia está inata uma enteléquia que domina todas as mudanças de formas européias e lhe confere o sentido de uma evolução em direção a um pólo eterno (...). O télos espiritual da humanidade européia, no qual está compreendido o télos particular das nações singulares e dos homens individuais, situa-se num infinito, é uma idéia infinita, para a qual tende, por assim dizer, o vir-a-ser espiritual global. À medida que, no próprio desenvolvimento, se torna consciente como télos, torna-se também meta prática da vontade (Willensziel), iniciando com isso uma nova forma de evolução, colocada sob a direção de normas e idéias normativas (Husserl, 2002, p. 71-72).

O conceito de "mundo da vida" serve a Husserl para uma crítica radical das ciências, cuja idealização já é resultado de métodos de conhecimento fundados em nossa experiência imediata, tais como o espaço exato da geometria, o tempo exato da física ou ainda a causalidade exata. É claro que Husserl quer questionar as certezas ingênuas das ciências. Embora argumente apenas de maneira sistemática, sua teoria do mundo da vida, na perspectiva da história da ciência, prepara o solo, uma vez que a questão da gênese de certos paradigmas científicos só encontra solução histórica. Husserl chama a atenção para experiências pré-científicas não menos legítimas que a aceitação de modelos de conhecimento científico. A rigor, como instâncias de fundamentação última, tais experiências até são mais importantes.

Segundo Husserl, também é preciso colocar entre parênteses o mundo resultante da visão das ciências modernas, pois tal visão também é elaborada a partir da vida natural. A própria ciência deve ser compreendida como uma determinada práxis da vida na qual, sob determinadas condições históricas, nasceu como formação subjetiva 
de uma práxis teórico-lógica especial. A vida moderna, sua consciência científica e cultural, é apenas uma entre outras possíveis.

Relativizando, pergunta por aquilo que é comum e possibilita uma comunicação entre todas as culturas humanas. Analisando a crise da cultura européia, Husserl constata que comum é o Lebenswelt (mundo da vida). Dele emerge o próprio mundo da ciência. Husserl afirma:

O investigador da natureza não se dá conta de que o fundamento permanente de seu trabalho mental, subjetivo, é o mundo circundante (Lebensumwelt) vital, que constantemente é pressuposto como base, como terreno da atividade, sobre o qual suas perguntas e seus métodos de pensar adquirem um sentido (Husserl, 2002, p. 90).

O recurso ao mundo da vida e à análise de sua estrutura impede que formas culturais, historicamente condicionadas, sejam hipostasiadas como a priori. Por outro lado, indica a linha mestra das atividades da subjetividade transcendental na constituição do mundo da vida. A fenomenologia é conhecimento das estruturas essenciais da vida transcendental como sendo o devir heraclitiano. Nesse sentido, fenomenologia é experiência transcendental que visa a experiência absoluta. Por isso Husserl considera-a acabamento do racionalismo do qual o racionalismo histórico não passa de pálida pré-forma.

Mas, na fenomenologia, também permanecem a verdade do empirismo, a justificação da constituição imediata do mundo da vida, da subjetividade e sua dóxa. É o fundamento no qual as oposições, entre racionalismo e empirismo, têm suas raízes comuns. A subjetividade transcendental é absoluta e se manifesta com suas estruturas essenciais no processo teleológico da história. Entretanto, indagar do sentido da história é tema da metafísica, que Husserl não chegou a desenvolver.

As concepções da fenomenologia, apresentadas por alguns contemporâneos e seguidores de Husserl, em grande parte são incompatíveis com sua concepção transcendental-idealista. Alguns fenomenólogos aceitaram as teses husserlianas da fenomenologia como atitude e método, a visão das essências, mas não assumiram o recurso ao mundo (pré-científico) da vida, ao vínculo situacional e ao horizonte da vida humana, seu conceito de corporalidade, etc. Em parte, acompanharam a redução fenomenológica e a redução eidética, mas não a redução transcendental como condição a priori do conhecimento filosófico e científico.

Em síntese, Husserl não encontrou um continuador de sua filosofia, ou seja, como ele a entendia. Apesar disso, em meados do século XX, quando a fenomenologia já parecia condenada ao esquecimento, renasceu o interesse por ela.

\section{Referências Bibliográficas}

Husserl, E. (1965). A Filosofia como Ciência de Rigor, Coimbra: Atlântida

Husserl, E. (1976). Die Krisis der europäischen Wissenschaften und die transzendentale Phänomenologie (Husserliana v. 6). Haag: Martinus Nijhoff.

Husserl, E. (s/d). Meditações Cartesianas. Porto: Rés.

Husserl, E. (1986). A Idéia da Fenomenologia, Lisboa: Edições 70.

Husserl, E. (1992). Conferências de Paris. Lisboa: Edições 70.

Husserl, E. (1996). Investigações Lógicas: $6^{a}$. Investigação. São Paulo: Nova Cultural.

Husserl, E. (2002). A Crise da Humanidade Européia e a Filosofia. Porto Alegre: Edipucrs.

Mittelstrass, J. (1995) (Org.). Enzyklopädie: Philosophie und Wissenschaftstheorie. Stuttgart-Weimar: Metzler (verbetes: Husserl e Phänomenologie), v. 2 e 3.

Ritter, J. \& Gründer K. (1989) (Org.). Historisches Wörterbuch der Philosophie. Basel: Schwabe \& CoAG Verlag (verbete Phänomenologie), v. 7.

Schneider, N. (1998). Erkenntnistheorie im 20. Jahrhundert. Stuttgart: Reclam.

Urbano Zilles - Bacharelado em Filosofia pela Faculdade de Filosofia Nossa Senhora Imaculada Conceição (1962); Licenciatura em Filosofia pela Universidade Regional do Noroeste do Estado do Rio Grande do Sul (1971); Bacharelado em Teologia pela Theologische Hochschule Beuron (1966); Doutorado em Teologia pela Universitat Munster (WestfalischeWilhelms) (1969); Atualmente é Professor Titular da Pontifícia Universidade Católica do Rio Grande do Sul, Membro de Corpo Editorial da revista "Veritas" (PUC-RS), Membro de Corpo Editorial da revista "Teocomunicação" (PUC-RS) e Membro de Corpo Editorial da "Revista Análise \& Síntese" (Revista de Filosofia e Teologia da Faculdade São Bento, BA). É o tradutor do texto de Husserl, A Crise da Humanidade Européia e a Filosofia (Editora da PUC-RS, 1996).

Recebido em 19.09.07 Aceito em 24.11.07 